\title{
From the Guest Editors
}

\author{
Helena Röcklinsberg • Mickey Gjerris
}

Accepted: 10 June 2010/Published online: 1 July 2010

(C) Springer Science+Business Media B.V. 2010

This special issue is edited on basis of the work done within the Nordic Network of Agriculture and Food Ethics in the period 2006-2009. The network was established as a Nordic platform to EurSafe in Oslo 2006. Thanks to funding from NordForsk the Nordic Network of Agriculture and Food Ethics has enabled dispersed research groups and individual PhD-students with interest in interdisciplinary work on ethics in the agri-aquaculture field to meet and present current research at two workshops and other informal meetings. Two interdisciplinary PhD-courses have been held in Vilnius with PhD-students from more than eight countries, and senior teachers from several Nordic countries and North America.

Agri- and aquacultural research and food ethics covers a wide range of issues and disciplines and offer a complex field due to its interdisciplinary character. In the Nordic Network of Agriculture and Food Ethics doctoral students from science, humanities, and social sciences have been given opportunities to grow into the interdisciplinary way of working, thinking, and talking. Both young and senior researchers have benefited from new research contacts and been able to investigate new interdisciplinary approaches. In addition, we have been able to create an overview of the Nordic research capacities in this field. This issue of the Journal of Agricultural and Environmental Ethics, therefore, serves as a presentation of some of the main current Nordic research areas and focus points.

The Nordic countries have been privileged for many years with regard to food issues, i.e., there has not been problems with food scarcity, large food safety

H. Röcklinsberg ( ()

Department of Animal Environment and Health, Swedish University of Agricultural Sciences

(SLU), Box 7068, 75007 Uppsala, Sweden

e-mail: Helena.Rocklinsberg@hmh.slu.se

\section{Gjerris}

Danish Centre for Bioethics and Risk Assessment, University of Copenhagen,

Rolighedsvej 25, 1958 Frederiksberg C, Denmark

e-mail: mgj@life.ku.dk 
scandals, nor radical effects of climate changes as of yet. But due to increasing interdependence between societies, nations, and the changes in the conditions for agricultural production due to climate change, these issues are highly relevant for Nordic research in the field of agricultural and food domains, both from a natural science perspective and from a social and ethical perspective. Among today's Nordic researchers in this field, one can detect a high awareness of injustices in global food supply (as related to climate changes) combined with a growing interest in discussing methods and approaches to best possible solutions.

There are different groups in the discussions in this area. Some argue for technological solutions to the challenges ahead while others look into more sustainable practices and changed consumption patterns. This inevitably leads into discussions of ethics, methods, and strategies. However, such questions cannot be settled easily - if at all. To build a broad and meaningful societal dialogue around these issues that touch upon deep seated values, it is necessary to draw on various fields of research in an interdisciplinary manner. Social and ethical issues like justice and responsibility in a world of climate change, ecosystem values, and animal interests and rights are just some of the important issues within the agriaqua-food sector today where the facilitation of such discussions is necessary.

In this issue the contributions link to these discussions in different ways, and all contributions relate to animal welfare issues in different ways. Nielsen et al. discusses different frameworks of integrating animal welfare parameters into the breeding goals for farm animals. As the concept of animal welfare is a complex issue the authors argue for a multidisciplinary as well as multi-stakeholder approach to the problem, concluding that even though the necessary tools for including animal welfare into breeding strategies for farm animals in this comprehensive manner have been developed, the practical implementation is yet to be achieved.

The traditional Nordic research topic animal welfare of farm animals is now also becoming more and more relevant in aquaculture as production continues to increase and intensify. This issue is discussed in the paper by Olesen et al. The paper contains an overview of breeding goals and values in salmon aquaculture and discusses the complex issue of what balance to reach for between animal welfare, economics, and environmental concerns. This is relevant not only for the aquaculture producing countries (including production of fish meals and fish oils), but also for the consumers at large in terms of a general food ethics.

Gjerris et al. discuss the issue in light of climate change, looking at the ethical challenges to animal production and evaluating different strategies of adaptation and mitigation. The paper concludes by discussing the possible contributions of a virtue ethics approach to issues such as intensified animal production, global food safety, sustainability, animal welfare, and human responsibility and freedom to act.

Forsberg discusses how theoretical statements and practice are related to each other in animal welfare issues. This is done using the Norwegian Animal Welfare Act from January 2010 as an example. Forsberg discusses the new concepts used: intrinsic value and respect for the individual animal, and argues that if the legislation protecting the intrinsic value of animals is to have an effect, measurements in order to promote a changed attitude and handling in industrial farming practices are needed in addition to legislative changes. 
Algers et al. consider the challenge of communication of ethical values and ideals between different stakeholders in society. They investigate open web-based tools for teaching animal welfare to traditional students such as veterinarians and argue they have been continuously developed and are well suited to meet the need for education in animal welfare among more diverse groups of consumers and citizens. In this way they can help facilitate an international discourse on animal welfare.

The traditional Nordic research topic animal welfare of farm animals is now also becoming more and more relevant in aquaculture as production continues to increase and intensify. This issue is discussed in the paper by Olesen et al. The paper contain an overview of breeding goals and values in salmon aquaculture and discusses the complex issue of what balance to reach for between animal welfare, economics, and environmental concerns. This is relevant not only for the aquaculture producing countries (including production of fish meals and fish oils), but also for the consumers at large in terms of a general food ethics.

Finally Larssaether also applies a specific approach to animal welfare issues by scrutinizing how organic milk was introduced and developed on the food market in Norway from the consumer perspective. Through an Actor-Network-Approach Larssaether argues that the borders between organic and conventional are decided not only by physical processes but also by societal practices, e.g. how organic milk product are seen and placed in relation to conventional milk products by different actors within the Norwegian milk chain from producers to consumers.

As a post scriptum we would like to express our gratefulness to Vonne Lund, who was a strong driving force in establishing NordNafe, and together with Helena Röcklinsberg was responsible for making a publication within the Network. In June 2009 Vonne Lund passed away, leaving those who knew her and worked with her sad and full of rain. (See Memorial in this issue). In order to maintain her visions and energy the Network decided to continue with the publication, and Mickey Gjerris became a co-editor instead. We are happy to present this issue of insights into Nordic research on Argicultural and Food Ethics in honor of Vonne Lund-a colleague and friend who is and will be missed. 